\title{
Author Correction: Fine Structure of Posterior Alpha Rhythm in Human EEG: Frequency Components, Their Cortical Sources, and Temporal Behavior
}

\author{
Elham Barzegaran ${ }^{1,2}$, VladimirY. Vildavski $i^{3}$ \& Maria G. Knyazeva ${ }^{1,2}$ \\ Correction to: Scientific Reports https://doi.org/10.1038/s41598-017-08421-z, published online 15 August 2017
}

This Article contains errors in the Reference list. Reference 19 is incorrectly listed as 'Nolte, G. et al. Identifying true brain interaction from EEG data using the imaginary part of coherency. Clinical Neurophysiology 115, 2292-2307 (2004)'. The correct reference 19 appears below as ref. ${ }^{1}$.

Additionally, reference 45 is incorrectly cited in its second instance. The correct reference 45 appears below as ref. $^{2}$.

Consequently, in the Discussion section,

'The recently reported decomposition of MEG activity by Independent Component Analysis in the cortical source space revealed occipito-parietal $10 \mathrm{~Hz}$ components in all the subjects, and temporal $8-10 \mathrm{~Hz}$ components in some of them ${ }^{45}$.

should read:

'The recently reported decomposition of MEG activity by Independent Component Analysis in the cortical source space revealed occipito-parietal $10 \mathrm{~Hz}$ components in all the subjects, and temporal $8-10 \mathrm{~Hz}$ components in some of them ${ }^{2}$.

\section{References}

1. Lodder, S. S. \& van Putten, M. J. Automated EEG analysis: Characterizing the posterior dominant rhythm. Journal of neuroscience methods 200, 86-93 (2011).

2. Ramkumar, P., Parkkonen, L., Hari, R. \& Hyvärinen, A. Characterization of neuromagnetic brain rhythms over time scales of minutes using spatial independent component analysis. Human brain mapping 33, 1648-1662 (2012).

${ }^{1}$ Laboratoire de recherche en neuroimagerie (LREN), Department of Clinical Neurosciences, Lausanne University Hospital and University of Lausanne, Lausanne, Switzerland. ${ }^{2}$ Leenaards Memory Centre and Department of Clinical Neurosciences, Centre Hospitalier Universitaire Vaudois and University of Lausanne, Lausanne, Switzerland. ${ }^{3}$ Department of Psychology, Stanford University, Stanford, CA, USA. Correspondence and requests for materials should be addressed to M.G.K. (email: Maria.Knyazeva@chuv.ch) 
(i) Open Access This article is licensed under a Creative Commons Attribution 4.0 International License, which permits use, sharing, adaptation, distribution and reproduction in any medium or format, as long as you give appropriate credit to the original author(s) and the source, provide a link to the Creative Commons license, and indicate if changes were made. The images or other third party material in this article are included in the article's Creative Commons license, unless indicated otherwise in a credit line to the material. If material is not included in the article's Creative Commons license and your intended use is not permitted by statutory regulation or exceeds the permitted use, you will need to obtain permission directly from the copyright holder. To view a copy of this license, visit http://creativecommons.org/licenses/by/4.0/.

(C) The Author(s) 2018 